\title{
Evaluación de los riesgos de trabajo en el centro quirúrgico del Hospital Quito N.-1 Policía Nacional
}

Evaluation of the risks of work in the surgical center of the Hospital Quito N.-1 National Police

Laura Cristina Palacios Jiménez ${ }^{1}$, Eduardo Javier Palacios Jiménez ${ }^{2}$, Verónica Cáceres ${ }^{3}$

Recibido: 10-02-2019 / Revisado: 15-02-209 /Aceptado: 04-03-2019/ Publicado: 14-06-2019

\begin{abstract}
.
DOI: https://doi.org/10.33262/cienciadigital.v3i1.1.358

The aim of this work was the evaluation of the occupational risks of the surgical staff of a Hospital Quito N.- 1 Policía Nacional. For this, the work facilities were visited to make a recognition of the place and, with the communication and consultation to the personnel, the working conditions were described to obtain the identification of the risk factors. Most of the risks reached an acceptable level of risk in all job positions, $54.6 \%$ of the total, and very high risks were presented only in the job positions of Anesthesiologist and General Services, which represents the $2.1 \%$ of the identified risks. $100 \%$ of the hazards by major emergencies reached a significant risk level. The risk factors by biological agents reached $82.4 \%$ of the notable risks. Psychosocial risk factors reached $22.2 \%$ of the notable risks and $27.8 \%$ of the possible risks, which is why these would continue in the next order of attention of occupational risks and a detailed evaluation is recommended.
\end{abstract}

Keywords: Evaluation, risks, work, surgical, Hospital, National Police.

\section{Resumen.}

El presente trabajo tuvo como objetivo evaluar los riesgos de trabajo del personal del centro quirúrgico del Hospital de Quito N.- 1 de la Policía Nacional. Para esto se visitaron las instalaciones de trabajo para hacer un reconocimiento del lugar $y$, con la comunicación y consulta al personal, se describieron las condiciones de trabajo para arrancar con la identificación de los factores de riesgos. La mayoría de los riesgos alcanzaron un nivel de riesgo aceptable en todos los puestos de trabajo,

\footnotetext{
${ }^{1}$ Afiliación (Universidad, Carrera o Facultad), Ambato, Ecuador, email (preferente institucional)

2 Escuela Superior Politécnica de Chimborazo, Facultad de Recursos Naturales. Riobamba, Ecuador.xxxx@espoch.edu.ec

${ }^{3}$ Escuela Superior Politécnica de Chimborazo, Facultad de Recursos Naturales. Riobamba, Ecuador. xxxxx@yahoo.es
} 
$54,6 \%$ del total de riesgos identificados, y se presentaron riesgos muy altos únicamente en los puestos de Trabajo de Anestesiólogo y Servicios generales, los cuales representan el 2,1\% de los riesgos identificados. El $100 \%$ de los peligros por emergencias mayores, alcanzaron un riesgo notable. Los factores de riesgo por agentes biológicos, se ubicaron en el 82,4\% de los riesgos notables. Los factores de riesgo psicosociales se encuentran en el $22,2 \%$ de los riesgos notables y el 27,8 $\%$ de los riesgos posibles, razón por la cual estos seguirían en el siguiente orden de atención de peligros laborales y se recomienda una evaluación detallada de los mismos.

Palabras claves: Evaluación, riesgos, trabajo, quirúrgico, Hospital, Policía Nacional.

\section{Introducción.}

En la literatura académica poco o nada se encuentra en relación con una evaluación adecuada de los efectos crónicos que pueden presentarse en los profesionales de la salud que trabajan en los hospitales, especialmente de los trabajadores que están mayormente expuestos a estos agentes químicos y biológicos de alto riesgo, ni de las condiciones ergonómicas que requieren para salvaguardar su salud, como son el personal que trabaja en quirófanos (Organización Iberoamericana de Seguridad Social, 2004).

La situación del personal de los centros quirúrgicos en particular es más preocupante ya que el nivel de exposición y cercanía a estas fuentes de agentes peligrosos y condiciones adversas de trabajo son considerablemente mayores debido a que deben administrar los medicamentos, manipular el instrumental principal y monitorear los signos vitales de los pacientes en los respectivos equipos médicos y actuar de manera inmediata ante cualquier desviación de las variables de control en las cirugías. En ese sentido, estos trabajadores están expuestos a una serie de riesgos laborales, los que en algunos casos derivan en graves consecuencias sobre su salud, con repercusiones en los ámbitos personal, familiar, laboral y social. Por tanto, esta situación configura en que sean considerados como trabajadores de la salud de alto riesgo profesional (Organización Iberoamericana de Seguridad Social, 2004).

Este desconocimiento de las condiciones de trabajo y posibles propuestas de intervención para reducir los riesgos laborales del personal de centros quirúrgicos en instituciones hospitalarias del Ecuador se ha hecho más evidente porque algunos trabajadores están presentando diversas patologías particulares que pueden ser consideradas enfermedades profesionales lo que ha ocasionado por una parte preocupación de estos trabajadores por su bienestar y salud.

La mejora de la calidad de vida se deriva del avance social y de las tecnologías. Esto también en el ámbito laboral con la reducción o eliminación de los problemas existentes de la producción. Pero, por otro lado, algunos problemas persisten, unos se van agudizado mientras otros van apareciendo, debido a los cambios en los procesos operativos, avances 
tecnológicos u organizativos. De aquí la necesidad de la identificación, evaluación y control de estos problemas (Gómez, 2017, pp. 5, 6).

Estos problemas se derivan de elementos que pueden incidir en el desarrollo del trabajo, los conocidos factores de riesgos laborales, o peligros del trabajo, los cuales se definen como condiciones o situaciones del trabajo que pueden perjudicar la integridad o salud de los trabajadores. Es así que estos peligros pueden eliminar el equilibrio mental, social o físico del trabajador (AENOR, 2011, p. 14; Gómez, 2017, pp. 7).

Esta normativa establece las líneas de actuación para llevar un control adecuado de los factores de riesgo de forma que pueda asegurarse el estado de salud del trabajador, como objetivo más importante cuando se habla de prevención. (AENOR, 2011, p. 11)

La prevención de riesgos laborales está concebida en tres ramas preventivas (AENOR, 2011, p. 14).

\section{Seguridad en el Trabajo}

Corresponde al conjunto de técnicas preventivas no médicas cuyo fin es la identificación de cualquier tipo de situación que pueda originar accidentes de trabajo, evaluarlas y tomar medidas correctivas para evitar o minimizar los posibles daños a la salud. Para este objetivo deben investigar las condiciones de seguridad influyen sobre la accidentabilidad, como por ejemplo elementos cortantes, móviles, combustibles, electrificados, etc., y cuyo control requiere del análisis de herramientas y máquinas, instalaciones eléctricas, equipos de transporte, condiciones de almacenamiento, dimensionamiento de los locales, etc. (AENOR, 2011, p. 15; Rubio, J. et al, 2005, p. 12).

\section{Higiene Industrial}

Engloba a agentes químicos, físicos y biológicos. Es decir, contaminantes como sustancias presentes en el ambiente laboral cuya inhalación o contacto pueden originar enfermedades profesionales, vibraciones, ruido, iluminación, condiciones termohigrométricas (temperatura, velocidad del aire, humedad, etc.), radiaciones, virus, bacterias, por lo cual deben considerarse sus efectos sobre la salud, metodologías de evaluación y posibles medidas de control. Es decir, la Higiene Industrial busca prevenir las enfermedades ocupacionales o profesionales (AENOR, 2011, p. 15).

\section{Ergonomía y Psicosociología Aplicada}

La Ergonomía trata los factores relacionados a las características del trabajo, elementos que plantean al trabajador esfuerzos físicos, estáticos como mantenimiento de una misma postura de trabajo o dinámicos como al manipular cargas, y mentales como el nivel de atención de la tarea). Por otro lado, la Psicosociología Aplicada trata los factores ligados a la organización del trabajo como lo son el clima laboral, la comunicación interna, el reparto de tareas, turnos y horarios, etc. (AENOR, 2011, p. 16). 


\section{Gestión del riesgo}

La Gestión del riesgo hace referencia a los principios, marco y procesos para una eficaz gestión del riesgo, lo cual contribuye al logro demostrable de objetivos y la mejora del desempeño en diferentes áreas, incluyendo Seguridad y Salud del Trabajo (ICONTEC, 2011, p. 9).

La gestión del riesgo parte de la comunicación y consulta con las partes involucradas, internas y externas, y debe mantenerse en todas las etapas de esta gestión. Esta es la base para establecer adecuadamente el contexto, garantizar el entendimiento y consideración de los intereses de todo el personal involucrado, identificar correctamente los riesgos y asegurar la aprobación y soporte del plan de intervención.

\section{Valoración del riesgo}

Corresponde al proceso total de identificación del riesgo, su análisis y posterior evaluación. Estas fases se definen a continuación (ICONTEC, 2011, pp. 21, 22):

a) Identificación del riesgo: La organización debe identificar las fuentes de riesgo, las diferentes áreas de impacto, los eventos o cambios en las circunstancias, sus causas y potenciales consecuencias. Como resultado se genera una lista íntegra de riesgos sobre la base de los eventos que podrían crear, degradar, aumentar, acelerar, prevenir o retardar el logro de los objetivos. Esta identificación debe incluir todos los riesgos, independientemente de si están o no bajo el control de la organización, e incluir un profundo examen de los posibles efectos colaterales de las consecuencias particulares.

b) Análisis del riesgo: Implica el desarrollo y comprensión del riesgo por lo cual brinda una entrada para su evaluación del riesgo y decidir si requieren o no ser intervenidos a través de métodos o estrategias más adecuados para su tratamiento. Este análisis involucra la consideración de sus fuentes y causas, consecuencias negativas y positivas, así como la probabilidad de ocurrencia de estas consecuencias. El grado de detalle del análisis de riesgo dependerá del tipo de riesgo, el objetivo del análisis y los datos, información recursos disponibles, pudiendo realizarse un análisis cualitativo, cuantitativo o una combinación de estos.

c) Evaluación del riesgo: Permite facilitar la toma de decisiones, con base en los resultados del análisis, sobre cuáles son los riesgos que deben ser intervenidos y el orden de intervención. En la evaluación se debe comparar la magnitud del riesgo observado durante el análisis y los criterios de aceptabilidad del riesgo. Además, las decisiones deben considerar el contexto más amplio del riesgo, los requisitos reglamentarios, legales, entre otros.

\section{Tratamiento del riesgo}

Involucra la selección de una o más alternativas para modificar los riesgos y su implementación, las cuales, una vez implementadas, suministran controles o modifican 
los riesgos. Este tratamiento corresponde a un proceso cíclico de valoración del mismo, la decisión sobre la aceptabilidad de los niveles de riesgo residual como tolerables, el planteamiento de un nuevo tratamiento del riesgo en caso de no ser tolerables y la valoración de la eficacia del nuevo tratamiento (ICONTEC, 2011, pp. 22, 23).

\section{Registro del proceso para la gestión del riesgo}

Cualquier actividad de la gestión del riesgo debe tener trazabilidad. Con este fin, los registros proporcionan la base para la mejora de las herramientas, los métodos proceso en su totalidad.

\section{Metodologia.}

En la literatura académica poco o nada se encuentra en relación con una evaluación adecuada de los efectos crónicos que pueden presentarse en los profesionales de la salud que trabajan en los hospitales, especialmente de los trabajadores que están mayormente expuestos a estos agentes químicos y biológicos de alto riesgo, ni de las condiciones ergonómicas que requieren para salvaguardar su salud, como son el personal que trabaja en quirófanos (Organización Iberoamericana de Seguridad Social, 2004).

La situación del personal de los centros quirúrgicos en particular es más preocupante ya que el nivel de exposición y cercanía a estas fuentes de agentes peligrosos y condiciones adversas de trabajo son considerablemente mayores debido a que deben administrar los medicamentos, manipular el instrumental principal y monitorear los signos vitales de los pacientes en los respectivos equipos médicos y actuar de manera inmediata ante cualquier desviación de las variables de control en las cirugías. En ese sentido, estos trabajadores están expuestos a una serie de riesgos laborales, los que en algunos casos derivan en graves consecuencias sobre su salud, con repercusiones en los ámbitos personal, familiar, laboral y social. Por tanto, esta situación configura en que sean considerados como trabajadores de la salud de alto riesgo profesional (Organización Iberoamericana de Seguridad Social, 2004).

Este desconocimiento de las condiciones de trabajo y posibles propuestas de intervención para reducir los riesgos laborales del personal de centros quirúrgicos en instituciones hospitalarias del Ecuador se ha hecho más evidente porque algunos trabajadores están presentando diversas patologías particulares que pueden ser consideradas enfermedades profesionales lo que ha ocasionado por una parte preocupación de estos trabajadores por su bienestar y salud.

La mejora de la calidad de vida se deriva del avance social y de las tecnologías. Esto también en el ámbito laboral con la reducción o eliminación de los problemas existentes de la producción. Pero, por otro lado, algunos problemas persisten, unos se van agudizado mientras otros van apareciendo, debido a los cambios en los procesos operativos, avances tecnológicos u organizativos. De aquí la necesidad de la identificación, evaluación y control de estos problemas (Gómez, 2017, pp. 5, 6).

Estos problemas se derivan de elementos que pueden incidir en el desarrollo del trabajo, los conocidos factores de riesgos laborales, o peligros del trabajo, los cuales se definen como condiciones o situaciones del trabajo que pueden perjudicar la integridad o salud 
de los trabajadores. Es así que estos peligros pueden eliminar el equilibrio mental, social o físico del trabajador (AENOR, 2011, p. 14; Gómez, 2017, pp. 7).

Esta normativa establece las líneas de actuación para llevar un control adecuado de los factores de riesgo de forma que pueda asegurarse el estado de salud del trabajador, como objetivo más importante cuando se habla de prevención. (AENOR, 2011, p. 11)

La prevención de riesgos laborales está concebida en tres ramas preventivas (AENOR, 2011, p. 14).

\section{Seguridad en el Trabajo}

Corresponde al conjunto de técnicas preventivas no médicas cuyo fin es la identificación de cualquier tipo de situación que pueda originar accidentes de trabajo, evaluarlas y tomar medidas correctivas para evitar o minimizar los posibles daños a la salud. Para este objetivo deben investigar las condiciones de seguridad influyen sobre la accidentabilidad, como por ejemplo elementos cortantes, móviles, combustibles, electrificados, etc., y cuyo control requiere del análisis de herramientas y máquinas, instalaciones eléctricas, equipos de transporte, condiciones de almacenamiento, dimensionamiento de los locales, etc. (AENOR, 2011, p. 15; Rubio, J. et al, 2005, p. 12).

\section{Higiene Industrial}

Engloba a agentes químicos, físicos y biológicos. Es decir, contaminantes como sustancias presentes en el ambiente laboral cuya inhalación o contacto pueden originar enfermedades profesionales, vibraciones, ruido, iluminación, condiciones termohigrométricas (temperatura, velocidad del aire, humedad, etc.), radiaciones, virus, bacterias, por lo cual deben considerarse sus efectos sobre la salud, metodologías de evaluación y posibles medidas de control. Es decir, la Higiene Industrial busca prevenir las enfermedades ocupacionales o profesionales (AENOR, 2011, p. 15).

\section{Ergonomía y Psicosociología Aplicada}

La Ergonomía trata los factores relacionados a las características del trabajo, elementos que plantean al trabajador esfuerzos físicos, estáticos como mantenimiento de una misma postura de trabajo o dinámicos como al manipular cargas, y mentales como el nivel de atención de la tarea). Por otro lado, la Psicosociología Aplicada trata los factores ligados a la organización del trabajo como lo son el clima laboral, la comunicación interna, el reparto de tareas, turnos y horarios, etc. (AENOR, 2011, p. 16).

Gestión del riesgo

La gestión del riesgo hace referencia a los principios, marco y procesos para una eficaz gestión del riesgo, lo cual contribuye al logro demostrable de objetivos y la mejora del desempeño en diferentes áreas, incluyendo Seguridad y Salud del Trabajo (ICONTEC, 2011, p. 9).

La gestión del riesgo parte de la comunicación y consulta con las partes involucradas, internas y externas, y debe mantenerse en todas las etapas de esta gestión. Esta es la base para establecer adecuadamente el contexto, garantizar el entendimiento y consideración 
de los intereses de todo el personal involucrado, identificar correctamente los riesgos y asegurar la aprobación y soporte del plan de intervención.

\section{Valoración del riesgo}

Corresponde al proceso total de identificación del riesgo, su análisis y posterior evaluación. Estas fases se definen a continuación (ICONTEC, 2011, pp. 21, 22):

a) Identificación del riesgo: La organización debe identificar las fuentes de riesgo, las diferentes áreas de impacto, los eventos o cambios en las circunstancias, sus causas y potenciales consecuencias. Como resultado se genera una lista íntegra de riesgos sobre la base de los eventos que podrían crear, degradar, aumentar, acelerar, prevenir o retardar el logro de los objetivos. Esta identificación debe incluir todos los riesgos, independientemente de si están o no bajo el control de la organización, e incluir un profundo examen de los posibles efectos colaterales de las consecuencias particulares.

b) Análisis del riesgo: Implica el desarrollo y comprensión del riesgo por lo cual brinda una entrada para su evaluación del riesgo y decidir si requieren o no ser intervenidos a través de métodos o estrategias más adecuados para su tratamiento. Este análisis involucra la consideración de sus fuentes y causas, consecuencias negativas y positivas, así como la probabilidad de ocurrencia de estas consecuencias. El grado de detalle del análisis de riesgo dependerá del tipo de riesgo, el objetivo del análisis y los datos, información recursos disponibles, pudiendo realizarse un análisis cualitativo, cuantitativo o una combinación de estos.

c) Evaluación del riesgo: Permite facilitar la toma de decisiones, con base en los resultados del análisis, sobre cuáles son los riesgos que deben ser intervenidos y el orden de intervención. En la evaluación se debe comparar la magnitud del riesgo observado durante el análisis y los criterios de aceptabilidad del riesgo. Además, las decisiones deben considerar el contexto más amplio del riesgo, los requisitos reglamentarios, legales, entre otros.

Tratamiento del riesgo

Involucra la selección de una o más alternativas para modificar los riesgos y su implementación, las cuales, una vez implementadas, suministran controles o modifican los riesgos. Este tratamiento corresponde a un proceso cíclico de valoración del mismo, la decisión sobre la aceptabilidad de los niveles de riesgo residual como tolerables, el planteamiento de un nuevo tratamiento del riesgo en caso de no ser tolerables y la valoración de la eficacia del nuevo tratamiento (ICONTEC, 2011, pp. 22, 23).

Registro del proceso para la gestión del riesgo

Cualquier actividad de la gestión del riesgo debe tener trazabilidad. Con este fin, los registros proporcionan la base para la mejora de las herramientas, los métodos proceso en su totalidad. 


\section{Resultados.}

Descripción de las condiciones de trabajo en el centro quirúrgico del hospital quito n.- 1 Policía Nacional

El Centro Quirúrgico en cuestión se encuentra ubicado en el segundo piso del edificio del Hospital, cuenta con un área de recepción de pacientes semiestéril en donde el personal auxiliar recibe a cada paciente, sea de emergencia o programado.

Cuenta con 4 quirófanos equipados con máquinas de anestesia y monitores, mesas quirúrgicas y lámparas cialíticas en regular estado. Además, existe un sistema de eliminación de gases y un sistema de aire acondicionado. Las paredes no cuentan con aislamiento de plomo ya que, en cirugías traumatológicas, en la cuales generalmente se emplea un intensificador de imagen, la energía ionizante de la fuente es convertida a positrones de baja energía de radiación. No se cuenta con muebles ergonómicos, cada quirófano dispone únicamente de dos taburetes metálicos, a pesar de que el promedio de personas que intervienen en las cirugías es de aproximadamente seis o siete. La sala de recuperación cuenta con ocho camas, dos escritorios y solo dos computadoras para todo el personal que entra a desarrollar las intervenciones quirúrgicas y que deben elaborar los documentos necesarios para las historias clínicas. Existe un área asignada para reuniones del equipo médico de las diferentes especialidades y una estación de enfermería solo con sillas metálicas. En total se cuenta con 25 auxiliares de enfermería, 10 enfermeras y 10 médicos anestesiólogos, además de los diferentes médicos especialistas que ingresan de acuerdo al día quirúrgico.

El área quirúrgica está ocupada de forma permanente por Médicos anestesiólogos, Enfermeras (instrumentistas), auxiliares de enfermería y personal de servicios generales. Debido a la peligrosidad de los productos químicos empleados, el área quirúrgica es totalmente cerrada, sin ningún tipo de ventana ni contacto físico con otras áreas, lo que implica un alto grado de estrés laboral.

\begin{tabular}{|l|l|l|}
\hline Puestos de trabajo & Actividades & Tareas \\
\hline \multirow{4}{*}{ Anestesiólogo } & $\begin{array}{l}\text { Chequeo } \\
\text { preanestésico }\end{array}$ & 1) Elaborar historia clínica \\
\cline { 2 - 3 } & \multirow{2}{*}{$\begin{array}{l}\text { Procedimiento } \\
\text { anestésico }\end{array}$} & 2) Examen físico \\
\hline & Postquirúrgica & 2) Mantenimiento anestésico \\
\hline & \multirow{4}{*}{ Enfermera } & 3) Despertar de la anestesia \\
\hline \multirow{4}{*}{ Auxiliar de enfermería anestésica }
\end{tabular}


Apoyo de limpieza y 2) Traslado de desechos infecciosos servicios generales

3) Mensajería

Tabla 1: actividades y tareas realizadas por los trabajadores

Fuente: elaboración propia

En la Tabla 1 se presentan las actividades y tareas realizadas por los trabajadores en el centro quirúrgico del Hospital Quito N.- 1 Policía Nacional, sobre las cuales se realizó la identificación y evaluación de los riesgos laborales.

Resumen de la identificación de peligros, evaluación y valoración de los riesgos con base a las actividades y tareas presentadas en la tabla 1, se completó la siguiente evaluación y valoración de los riesgos identificados en el presente trabajo.

\begin{tabular}{|c|c|c|c|c|c|c|c|c|}
\hline \multirow[b]{2}{*}{ 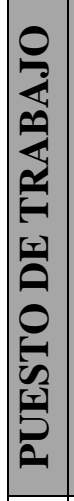 } & \multirow[b]{2}{*}{ 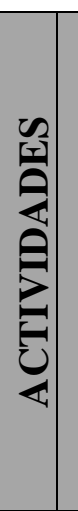 } & \multirow[b]{2}{*}{$\sum_{0}^{2}$} & \multicolumn{2}{|c|}{ PELIGRO } & \multicolumn{4}{|c|}{ RIESGO } \\
\hline & & & $\begin{array}{l}\text { DESCRI } \\
\text { PCIÓN }\end{array}$ & $\begin{array}{l}\text { CLASIFIC } \\
\text { ACIÓN }\end{array}$ & $\begin{array}{c}\text { METODO } \\
\text { LOGÍA } \\
\text { DE } \\
\text { EVALUA } \\
\text { CIÓN }\end{array}$ & $\begin{array}{c}\text { NIVEL } \\
\text { DE } \\
\text { RIESG } \\
\text { O O } \\
\text { MAGNI } \\
\text { TUD } \\
\text { MEDID } \\
\text { A }\end{array}$ & $\begin{array}{l}\text { CLASIFIC } \\
\text { ACIÓN }\end{array}$ & \begin{tabular}{|c} 
ACTUA \\
CIÓN \\
FRENT \\
E AL \\
RIESG \\
O
\end{tabular} \\
\hline \multirow{2}{*}{ 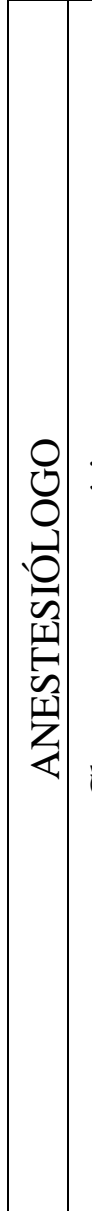 } & \multirow{2}{*}{\multicolumn{2}{|c|}{ 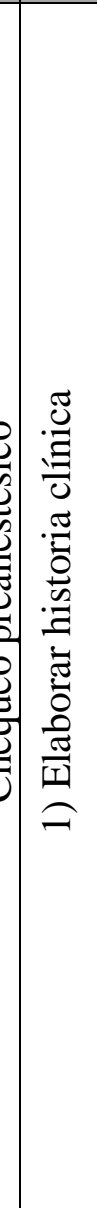 }} & Ruido & Físico & $\begin{array}{c}\text { Medición } \\
\text { de ruido } \\
\text { (dbA) }\end{array}$ & 49,8 & $\begin{array}{c}\text { Riesgo } \\
\text { aceptable }\end{array}$ & $\begin{array}{l}\text { Puede } \\
\text { omitirse } \\
\text { la } \\
\text { correcció } \\
\text { n } \\
\text { (máximo } \\
\text { permisibl } \\
\text { e en } \\
\text { jornada } \\
\text { de } 8 \mathrm{~h}, 85 \\
\text { dBA) }\end{array}$ \\
\hline & & & $\begin{array}{l}\text { Iluminaci } \\
\text { ón } \\
\text { insuficien } \\
\text { te }\end{array}$ & Físico & $\begin{array}{l}\text { Medición } \\
\text { de } \\
\text { iluminació } \\
\text { n (lux) }\end{array}$ & 10189 & $\begin{array}{c}\text { Riesgo } \\
\text { aceptable }\end{array}$ & $\begin{array}{l}\text { Puede } \\
\text { omitirse } \\
\text { la } \\
\text { correcció } \\
\text { n } \\
\text { (mínimo } \\
\text { recomen } \\
\text { dado } \\
10000 \\
\text { lux, } \\
\text { máximo }\end{array}$ \\
\hline
\end{tabular}




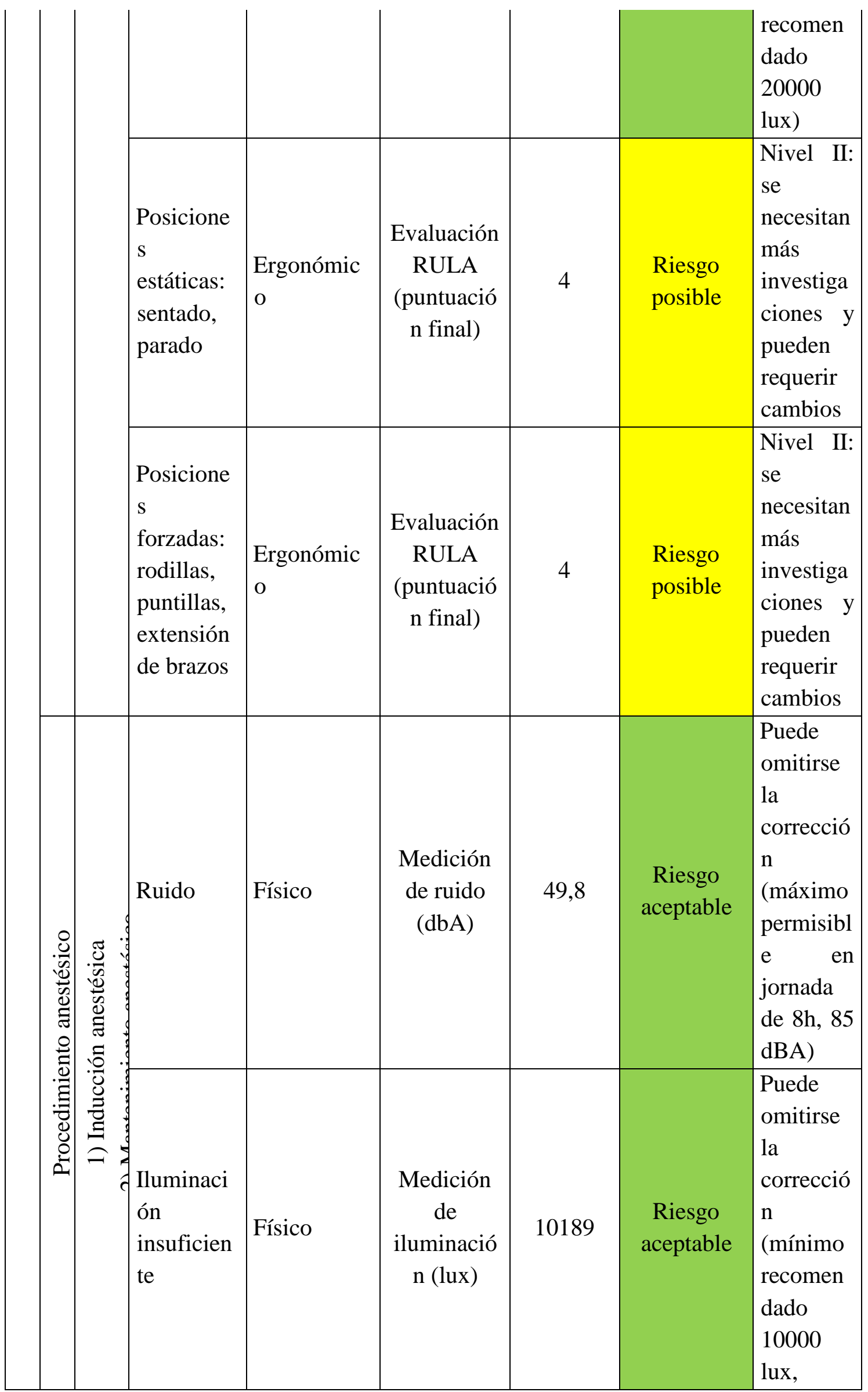




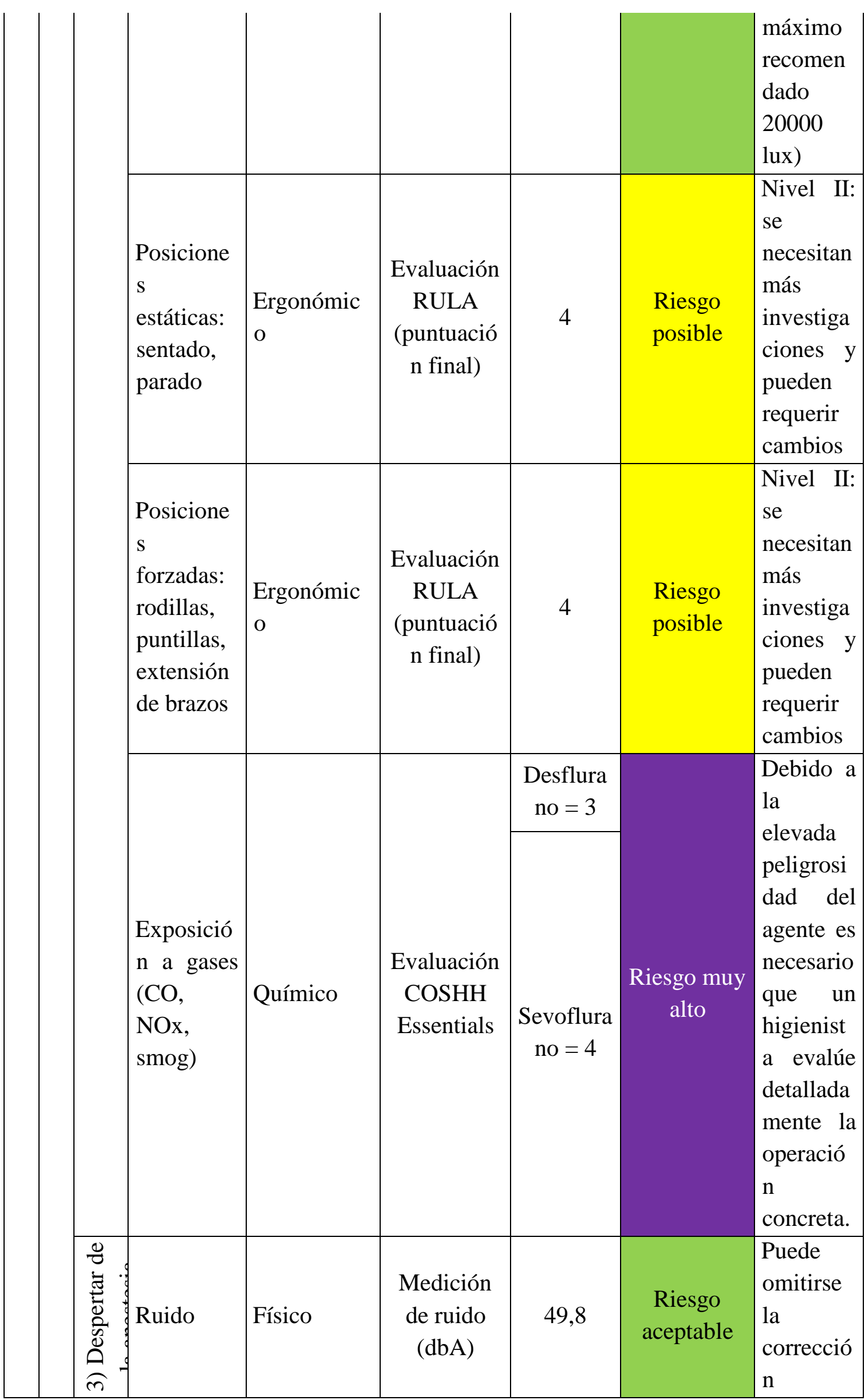




\begin{tabular}{|c|c|c|c|c|c|c|c|}
\hline & & & & & & & $\begin{array}{l}\text { (máximo } \\
\text { permisibl } \\
\text { e en } \\
\text { jornada } \\
\text { de } 8 \mathrm{~h}, 85 \\
\text { dBA) }\end{array}$ \\
\hline & & $\begin{array}{l}\text { Iluminaci } \\
\text { ón } \\
\text { insuficien } \\
\text { te }\end{array}$ & Físico & $\begin{array}{l}\text { Medición } \\
\text { de } \\
\text { iluminació } \\
\text { n (lux) }\end{array}$ & 10189 & $\begin{array}{c}\text { Riesgo } \\
\text { aceptable }\end{array}$ & $\begin{array}{l}\text { Puede } \\
\text { omitirse } \\
\text { la } \\
\text { correcció } \\
\text { n } \\
\text { (mínimo } \\
\text { recomen } \\
\text { dado } \\
10000 \\
\text { lux, } \\
\text { máximo } \\
\text { recomen } \\
\text { dado } \\
\text { 20000 } \\
\text { lux) }\end{array}$ \\
\hline & & $\begin{array}{l}\text { Posicione } \\
\text { s } \\
\text { estáticas: } \\
\text { sentado, } \\
\text { parado }\end{array}$ & $\begin{array}{l}\text { Ergonómic } \\
\text { o }\end{array}$ & $\begin{array}{c}\text { Evaluación } \\
\text { RULA } \\
\text { (puntuació } \\
\text { n final) }\end{array}$ & 4 & $\begin{array}{l}\text { Riesgo } \\
\text { posible }\end{array}$ & $\begin{array}{l}\text { Nivel II: } \\
\text { se } \\
\text { necesitan } \\
\text { más } \\
\text { investiga } \\
\text { ciones y } \\
\text { pueden } \\
\text { requerir } \\
\text { cambios }\end{array}$ \\
\hline & & $\begin{array}{l}\text { Posicione } \\
\text { s } \\
\text { forzadas: } \\
\text { rodillas, } \\
\text { puntillas, } \\
\text { extensión } \\
\text { de brazos }\end{array}$ & $\begin{array}{l}\text { Ergonómic } \\
\text { o }\end{array}$ & $\begin{array}{c}\text { Evaluación } \\
\text { RULA } \\
\text { (puntuació } \\
\text { n final) }\end{array}$ & 4 & $\begin{array}{l}\text { Riesgo } \\
\text { posible }\end{array}$ & $\begin{array}{l}\text { Nivel II: } \\
\text { se } \\
\text { necesitan } \\
\text { más } \\
\text { investiga } \\
\text { ciones y } \\
\text { pueden } \\
\text { requerir } \\
\text { cambios }\end{array}$ \\
\hline $\begin{array}{l}0.0 \\
\vdots \\
\vdots \\
\vdots \\
0 \\
0 \\
0 \\
0 \\
0\end{array}$ & $\widehat{I}$ & Ruido & Físico & $\begin{array}{c}\text { Medición } \\
\text { de ruido } \\
(\mathrm{dbA})\end{array}$ & 49,8 & $\begin{array}{c}\text { Riesgo } \\
\text { aceptable }\end{array}$ & $\begin{array}{l}\text { Puede } \\
\text { omitirse } \\
\text { la } \\
\text { correcció }\end{array}$ \\
\hline
\end{tabular}




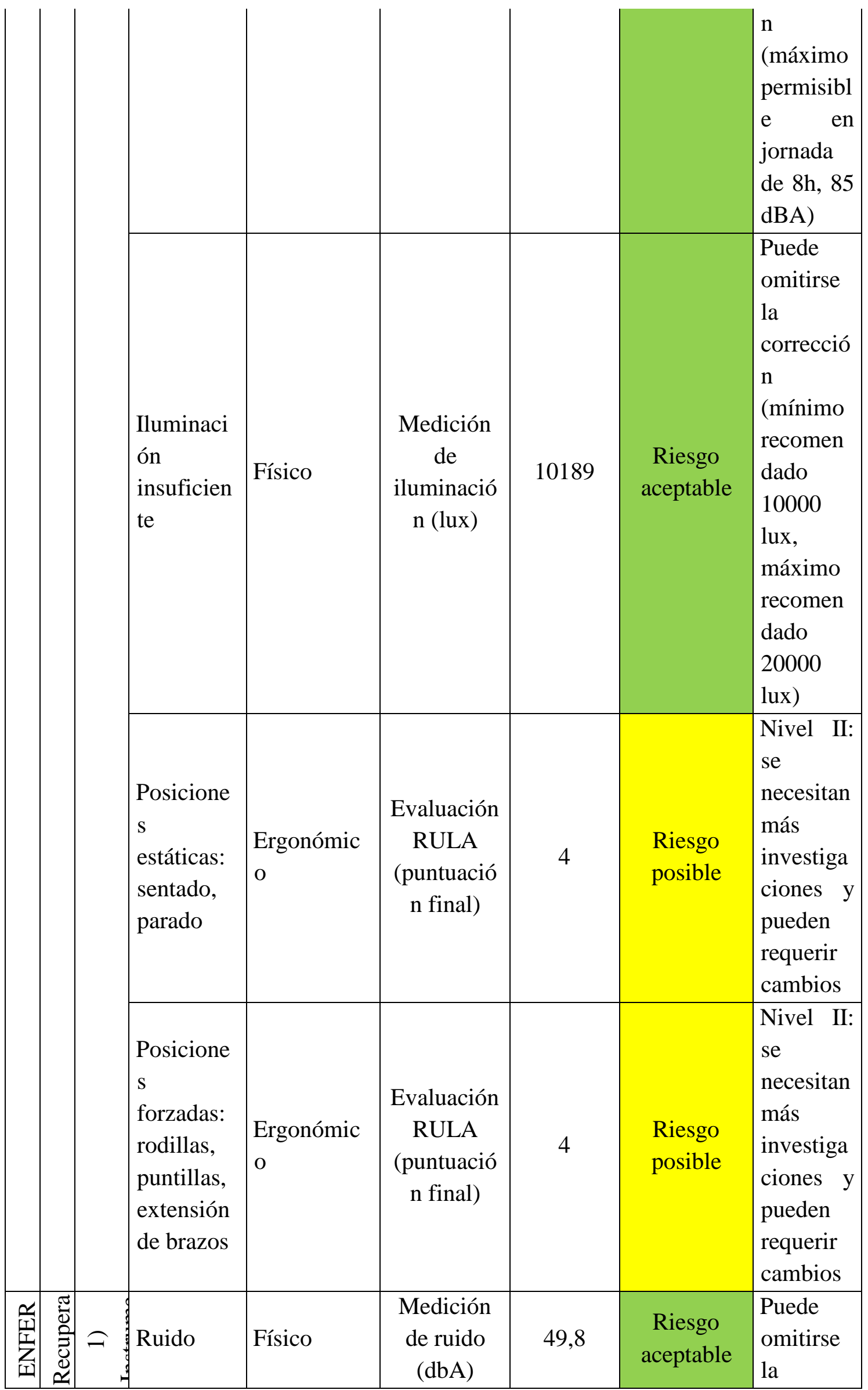




\begin{tabular}{|c|c|c|c|c|c|}
\hline & & & & & \begin{tabular}{|l} 
correcció \\
n \\
(máximo \\
permisibl \\
e en \\
jornada \\
de $8 \mathrm{~h}, 85$ \\
dBA)
\end{tabular} \\
\hline $\begin{array}{l}\text { Iluminaci } \\
\text { ón } \\
\text { insuficien } \\
\text { te }\end{array}$ & Físico & $\begin{array}{l}\text { Medición } \\
\text { de } \\
\text { iluminació } \\
\text { n (lux) }\end{array}$ & 10189 & $\begin{array}{l}\text { Riesgo } \\
\text { posible }\end{array}$ & $\begin{array}{l}\text { Puede } \\
\text { omitirse } \\
\text { la } \\
\text { correcció } \\
\text { n } \\
\text { (mínimo } \\
\text { recomen } \\
\text { dado } \\
10000 \\
\text { lux, } \\
\text { máximo } \\
\text { recomen } \\
\text { dado } \\
\text { 20000 } \\
\text { lux) }\end{array}$ \\
\hline $\begin{array}{l}\text { Posicione } \\
\text { s } \\
\text { estáticas: } \\
\text { sentado, } \\
\text { parado }\end{array}$ & $\begin{array}{l}\text { Ergonómic } \\
\text { o }\end{array}$ & $\begin{array}{c}\text { Evaluación } \\
\text { RULA } \\
\text { (puntuació } \\
\text { n final) }\end{array}$ & 4 & $\begin{array}{l}\text { Riesgo } \\
\text { posible }\end{array}$ & $\begin{array}{l}\text { Nivel II: } \\
\text { se } \\
\text { necesitan } \\
\text { más } \\
\text { investiga } \\
\text { ciones y } \\
\text { pueden } \\
\text { requerir } \\
\text { cambios }\end{array}$ \\
\hline $\begin{array}{l}\text { Posicione } \\
\text { s } \\
\text { forzadas: } \\
\text { rodillas, } \\
\text { puntillas, } \\
\text { extensión } \\
\text { de brazos }\end{array}$ & $\begin{array}{l}\text { Ergonómic } \\
\text { o }\end{array}$ & $\begin{array}{c}\text { Evaluación } \\
\text { RULA } \\
\text { (puntuació } \\
\text { n final) }\end{array}$ & 4 & $\begin{array}{l}\text { Riesgo } \\
\text { posible }\end{array}$ & $\begin{array}{l}\text { Nivel II: } \\
\text { se } \\
\text { necesitan } \\
\text { más } \\
\text { investiga } \\
\text { ciones y } \\
\text { pueden } \\
\text { requerir } \\
\text { cambios }\end{array}$ \\
\hline
\end{tabular}




\begin{tabular}{|c|c|c|c|c|c|c|}
\hline \multirow{4}{*}{ 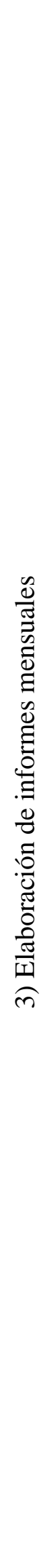 } & Ruido & Físico & $\begin{array}{c}\text { Medición } \\
\text { de ruido } \\
(\mathrm{dbA})\end{array}$ & 49,8 & $\begin{array}{c}\text { Riesgo } \\
\text { aceptable }\end{array}$ & $\begin{array}{l}\text { Puede } \\
\text { omitirse } \\
\text { la } \\
\text { correcció } \\
\text { n } \\
\text { (máximo } \\
\text { permisibl } \\
\text { e en } \\
\text { jornada } \\
\text { de } 8 \mathrm{~h}, 85 \\
\text { dBA) }\end{array}$ \\
\hline & $\begin{array}{l}\text { Iluminaci } \\
\text { ón } \\
\text { insuficien } \\
\text { te }\end{array}$ & Físico & $\begin{array}{c}\text { Medición } \\
\text { de } \\
\text { iluminació } \\
\text { n (lux) }\end{array}$ & 852 & $\begin{array}{l}\text { Riesgo } \\
\text { posible }\end{array}$ & \begin{tabular}{|l} 
Puede \\
omitirse \\
la \\
correcció \\
n \\
(mínimo \\
recomen \\
dado 500 \\
lux, \\
máximo \\
recomen \\
dado \\
1000 lux $)$
\end{tabular} \\
\hline & $\begin{array}{l}\text { Posicione } \\
\text { s } \\
\text { estáticas: } \\
\text { sentado, } \\
\text { parado }\end{array}$ & $\begin{array}{l}\text { Ergonómic } \\
\text { o }\end{array}$ & $\begin{array}{c}\text { Evaluación } \\
\text { RULA } \\
\text { (puntuació } \\
\text { n final) }\end{array}$ & 4 & $\begin{array}{l}\text { Riesgo } \\
\text { posible }\end{array}$ & $\begin{array}{l}\text { Nivel II: } \\
\text { se } \\
\text { necesitan } \\
\text { más } \\
\text { investiga } \\
\text { ciones y } \\
\text { pueden } \\
\text { requerir } \\
\text { cambios }\end{array}$ \\
\hline & $\begin{array}{l}\text { Posicione } \\
\mathrm{s} \\
\text { forzadas: } \\
\text { rodillas, } \\
\text { puntillas, } \\
\text { extensión } \\
\text { de brazos }\end{array}$ & $\begin{array}{l}\text { Ergonómic } \\
\text { o }\end{array}$ & $\begin{array}{c}\text { Evaluación } \\
\text { RULA } \\
\text { (puntuació } \\
\text { n final) }\end{array}$ & 4 & $\begin{array}{l}\text { Riesgo } \\
\text { posible }\end{array}$ & $\begin{array}{l}\text { Nivel II: } \\
\text { se } \\
\text { necesitan } \\
\text { más } \\
\text { investiga } \\
\text { ciones y } \\
\text { pueden } \\
\text { requerir } \\
\text { cambios }\end{array}$ \\
\hline
\end{tabular}




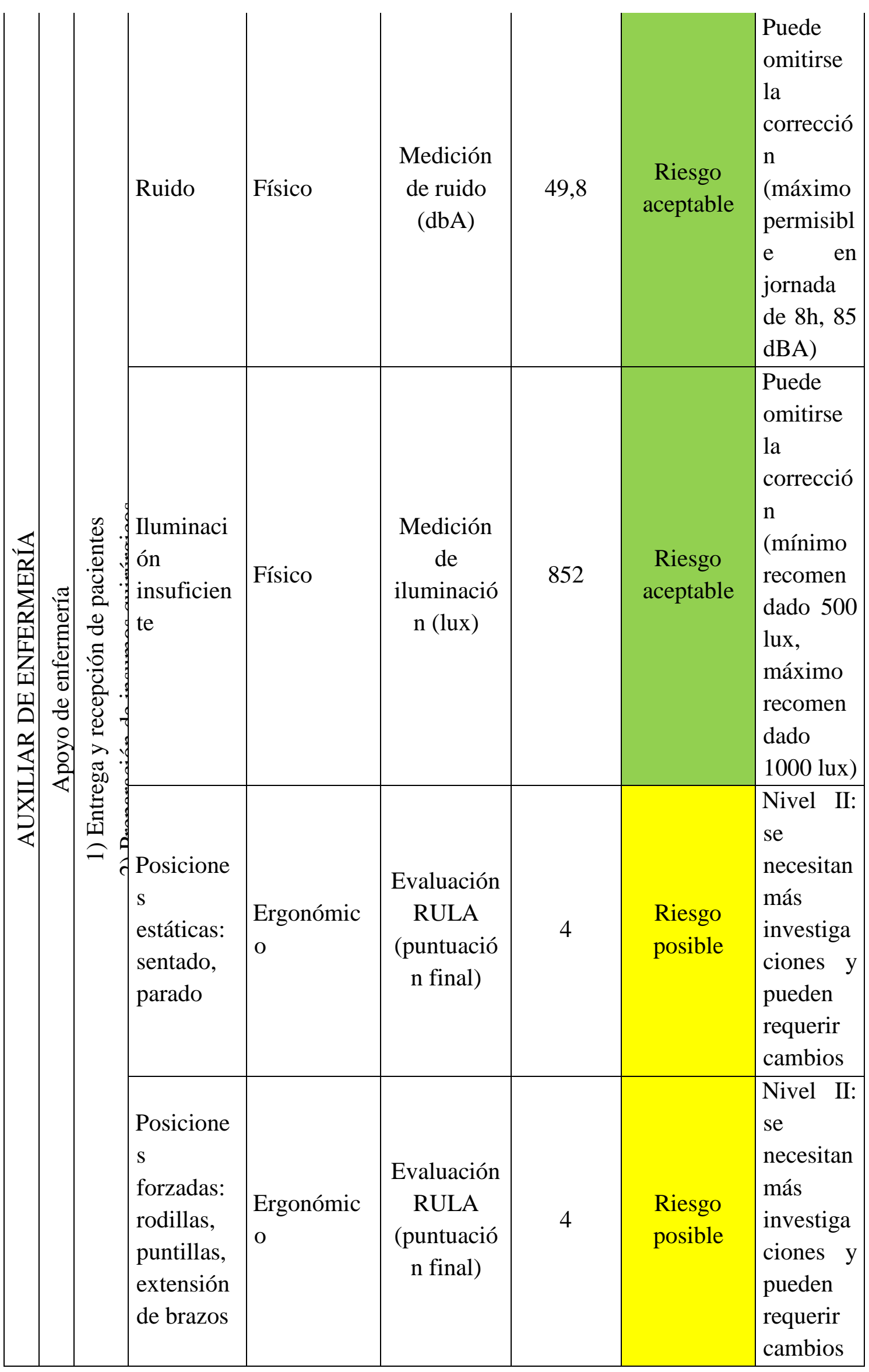




\begin{tabular}{|c|c|c|c|c|c|c|}
\hline \multirow{4}{*}{ 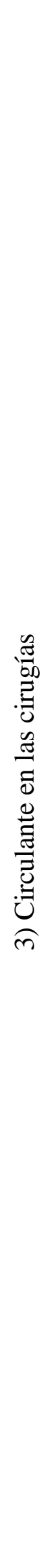 } & Ruido & Físico & $\begin{array}{c}\text { Medición } \\
\text { de ruido } \\
(\mathrm{dbA})\end{array}$ & 49,8 & $\begin{array}{c}\text { Riesgo } \\
\text { aceptable }\end{array}$ & $\begin{array}{l}\text { Puede } \\
\text { omitirse } \\
\text { la } \\
\text { correcció } \\
\text { n } \\
\text { (máximo } \\
\text { permisibl } \\
\text { e en } \\
\text { jornada } \\
\text { de } 8 \mathrm{~h}, 85 \\
\text { dBA) }\end{array}$ \\
\hline & $\begin{array}{l}\text { Iluminaci } \\
\text { ón } \\
\text { insuficien } \\
\text { te }\end{array}$ & Físico & $\begin{array}{c}\text { Medición } \\
\text { de } \\
\text { iluminació } \\
\text { n (lux) }\end{array}$ & 852 & $\begin{array}{c}\text { Riesgo } \\
\text { aceptable }\end{array}$ & \begin{tabular}{|l} 
Puede \\
omitirse \\
la \\
correcció \\
n \\
(mínimo \\
recomen \\
dado 500 \\
lux, \\
máximo \\
recomen \\
dado \\
1000 lux $)$
\end{tabular} \\
\hline & $\begin{array}{l}\text { Posicione } \\
\text { s } \\
\text { estáticas: } \\
\text { sentado, } \\
\text { parado }\end{array}$ & $\begin{array}{l}\text { Ergonómic } \\
\text { o }\end{array}$ & $\begin{array}{c}\text { Evaluación } \\
\text { RULA } \\
\text { (puntuació } \\
\text { n final) }\end{array}$ & 4 & $\begin{array}{l}\text { Riesgo } \\
\text { posible }\end{array}$ & $\begin{array}{l}\text { Nivel II: } \\
\text { se } \\
\text { necesitan } \\
\text { más } \\
\text { investiga } \\
\text { ciones y } \\
\text { pueden } \\
\text { requerir } \\
\text { cambios }\end{array}$ \\
\hline & $\begin{array}{l}\text { Posicione } \\
\mathrm{s} \\
\text { forzadas: } \\
\text { rodillas, } \\
\text { puntillas, } \\
\text { extensión } \\
\text { de brazos }\end{array}$ & $\begin{array}{l}\text { Ergonómic } \\
\text { o }\end{array}$ & $\begin{array}{c}\text { Evaluación } \\
\text { RULA } \\
\text { (puntuació } \\
\text { n final) }\end{array}$ & 4 & $\begin{array}{l}\text { Riesgo } \\
\text { posible }\end{array}$ & $\begin{array}{l}\text { Nivel II: } \\
\text { se } \\
\text { necesitan } \\
\text { más } \\
\text { investiga } \\
\text { ciones y } \\
\text { pueden } \\
\text { requerir } \\
\text { cambios }\end{array}$ \\
\hline
\end{tabular}




\begin{tabular}{|c|c|c|c|c|c|c|c|c|}
\hline \multirow{4}{*}{ 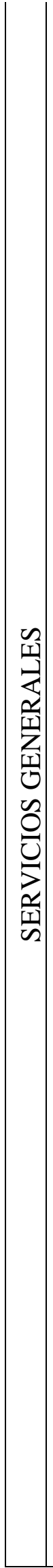 } & $\mid$ & & Ruido & Físico & $\begin{array}{c}\text { Medición } \\
\text { de ruido } \\
\text { (dbA) }\end{array}$ & 49,8 & $\begin{array}{c}\text { Riesgo } \\
\text { aceptable }\end{array}$ & $\begin{array}{l}\text { Puede } \\
\text { omitirse } \\
\text { la } \\
\text { correcció } \\
\text { n } \\
\text { (máximo } \\
\text { permisibl } \\
\text { e en } \\
\text { jornada } \\
\text { de } 8 \text { h, } 85 \\
\text { dBA) }\end{array}$ \\
\hline & 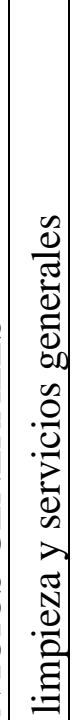 & 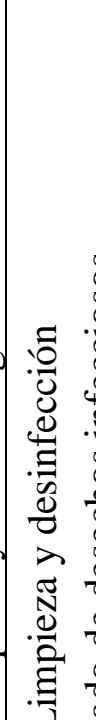 & $\begin{array}{l}\text { Iluminaci } \\
\text { ón } \\
\text { insuficien } \\
\text { te } \\
\end{array}$ & Físico & $\begin{array}{l}\text { Medición } \\
\text { de } \\
\text { iluminació } \\
\text { n (lux) }\end{array}$ & 852 & $\begin{array}{c}\text { Riesgo } \\
\text { aceptable }\end{array}$ & $\begin{array}{l}\text { Puede } \\
\text { omitirse } \\
\text { la } \\
\text { correcció } \\
\text { n } \\
\text { (mínimo } \\
\text { recomen } \\
\text { dado } 500 \\
\text { lux, } \\
\text { máximo } \\
\text { recomen } \\
\text { dado } \\
1000 \text { lux) }\end{array}$ \\
\hline & 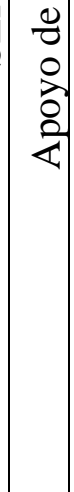 & $\begin{array}{r}\overrightarrow{2} \\
6 \\
6\end{array}$ & $\begin{array}{l}\text { Posicione } \\
\text { s } \\
\text { estáticas: } \\
\text { sentado, } \\
\text { parado }\end{array}$ & $\begin{array}{l}\text { Ergonómic } \\
\text { o }\end{array}$ & $\begin{array}{l}\text { Evaluación } \\
\text { RULA } \\
\text { (puntuació } \\
\text { n final) }\end{array}$ & 7 & $\begin{array}{l}\text { Riesgo muy } \\
\text { alto }\end{array}$ & $\begin{array}{l}\text { Nivel IV: } \\
\text { es } \\
\text { necesario } \\
\text { realizar } \\
\text { inmediat } \\
\text { amente } \\
\text { cambios } \\
\text { en la } \\
\text { tarea }\end{array}$ \\
\hline & & & $\begin{array}{l}\text { Posicione } \\
\text { s } \\
\text { forzadas: } \\
\text { rodillas, } \\
\text { puntillas, } \\
\text { extensión } \\
\text { de brazos }\end{array}$ & $\begin{array}{l}\text { Ergonómic } \\
\text { o }\end{array}$ & $\begin{array}{l}\text { Evaluación } \\
\text { RULA } \\
\text { (puntuació } \\
\text { n final) }\end{array}$ & 7 & $\begin{array}{l}\text { Riesgo muy } \\
\text { alto }\end{array}$ & $\begin{array}{l}\text { Nivel IV: } \\
\text { es } \\
\text { necesario } \\
\text { realizar } \\
\text { inmediat } \\
\text { amente } \\
\text { cambios } \\
\text { en la } \\
\text { tarea }\end{array}$ \\
\hline
\end{tabular}




\begin{tabular}{|c|c|c|c|c|c|c|}
\hline & $\begin{array}{l}\text { Sobreesfu } \\
\text { erzos }\end{array}$ & $\begin{array}{l}\text { Ergonómic } \\
\text { o }\end{array}$ & $\begin{array}{c}\text { Evaluación } \\
\text { NIOSH } \\
\text { (índice de } \\
\text { levantamie } \\
\text { nto) }\end{array}$ & 0,99 & $\begin{array}{c}\text { Riesgo } \\
\text { aceptable }\end{array}$ & \begin{tabular}{|l} 
La \\
mayoría \\
de \\
trabajado \\
$\mathrm{r}$ es que \\
realicen \\
este tipo \\
de tareas \\
no \\
deberían \\
tener \\
problema \\
s.
\end{tabular} \\
\hline \multirow{3}{*}{ 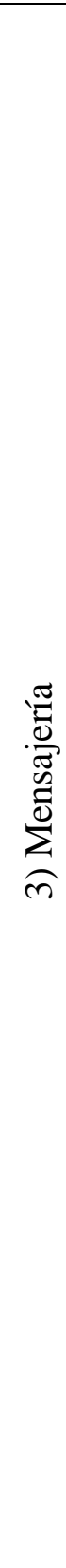 } & Ruido & Físico & $\begin{array}{c}\text { Medición } \\
\text { de ruido } \\
\text { (dbA) }\end{array}$ & 49,8 & $\begin{array}{c}\text { Riesgo } \\
\text { aceptable }\end{array}$ & $\begin{array}{l}\text { Puede } \\
\text { omitirse } \\
\text { la } \\
\text { correcció } \\
\text { n } \\
\text { (máximo } \\
\text { permisibl } \\
\text { e en } \\
\text { jornada } \\
\text { de } 8 \mathrm{~h}, 85 \\
\text { dBA) }\end{array}$ \\
\hline & $\begin{array}{l}\text { Iluminaci } \\
\text { ón } \\
\text { insuficien } \\
\text { te }\end{array}$ & Físico & $\begin{array}{l}\text { Medición } \\
\text { de } \\
\text { iluminació } \\
\text { n (lux) }\end{array}$ & 852 & $\begin{array}{c}\text { Riesgo } \\
\text { aceptable }\end{array}$ & \begin{tabular}{|l} 
Puede \\
omitirse \\
la \\
correcció \\
n \\
(mínimo \\
recomen \\
dado 500 \\
lux, \\
máximo \\
recomen \\
dado \\
1000 lux $)$
\end{tabular} \\
\hline & $\begin{array}{l}\text { Posicione } \\
\text { s } \\
\text { estáticas: } \\
\text { sentado, } \\
\text { parado }\end{array}$ & $\begin{array}{l}\text { Ergonómic } \\
\text { o }\end{array}$ & $\begin{array}{c}\text { Evaluación } \\
\text { RULA } \\
\text { (puntuació } \\
\text { n final) }\end{array}$ & 2 & $\begin{array}{c}\text { Riesgo } \\
\text { aceptable }\end{array}$ & $\begin{array}{l}\text { Nivel I: } \\
\text { la postura } \\
\text { es } \\
\text { aceptable } \\
\text { si no se } \\
\text { mantiene }\end{array}$ \\
\hline
\end{tabular}




\begin{tabular}{|c|c|c|c|c|c|}
\hline & & & & & $\begin{array}{l}\text { o repite } \\
\text { en } \\
\text { períodos } \\
\text { largos }\end{array}$ \\
\hline $\begin{array}{l}\text { Posicione } \\
\text { s } \\
\text { forzadas: } \\
\text { rodillas, } \\
\text { puntillas, } \\
\text { extensión } \\
\text { de brazos }\end{array}$ & $\begin{array}{l}\text { Ergonómic } \\
\text { o }\end{array}$ & $\begin{array}{c}\text { Evaluación } \\
\text { RULA } \\
\text { (puntuació } \\
\text { n final) }\end{array}$ & 2 & $\begin{array}{l}\text { Riesgo } \\
\text { aceptable }\end{array}$ & $\begin{array}{l}\text { Nivel I: } \\
\text { la postura } \\
\text { es } \\
\text { aceptable } \\
\text { si no se } \\
\text { mantiene } \\
\text { o repite } \\
\text { en } \\
\text { períodos } \\
\text { largos }\end{array}$ \\
\hline
\end{tabular}

Tabla 1. Resumen de evaluación de riesgos en el Hospital Quito N.-1 Policía Nacional, con varias metodologías ergonómicas, higiénicas o mediciones

En la Figura 1 se muestra la distribución de riesgos muy altos en los cuatro puestos de trabajo analizados. Estos comprenden el 8,5 \% de los 284 riesgos identificados, se puede verificar que estos corresponden a factores de riesgo químicos para el puesto de Anestesiólogo (100\% de estos factores) y factores de riesgo ergonómicos para el puesto de Servicios Generales (50\% de estos factores), respectivamente.

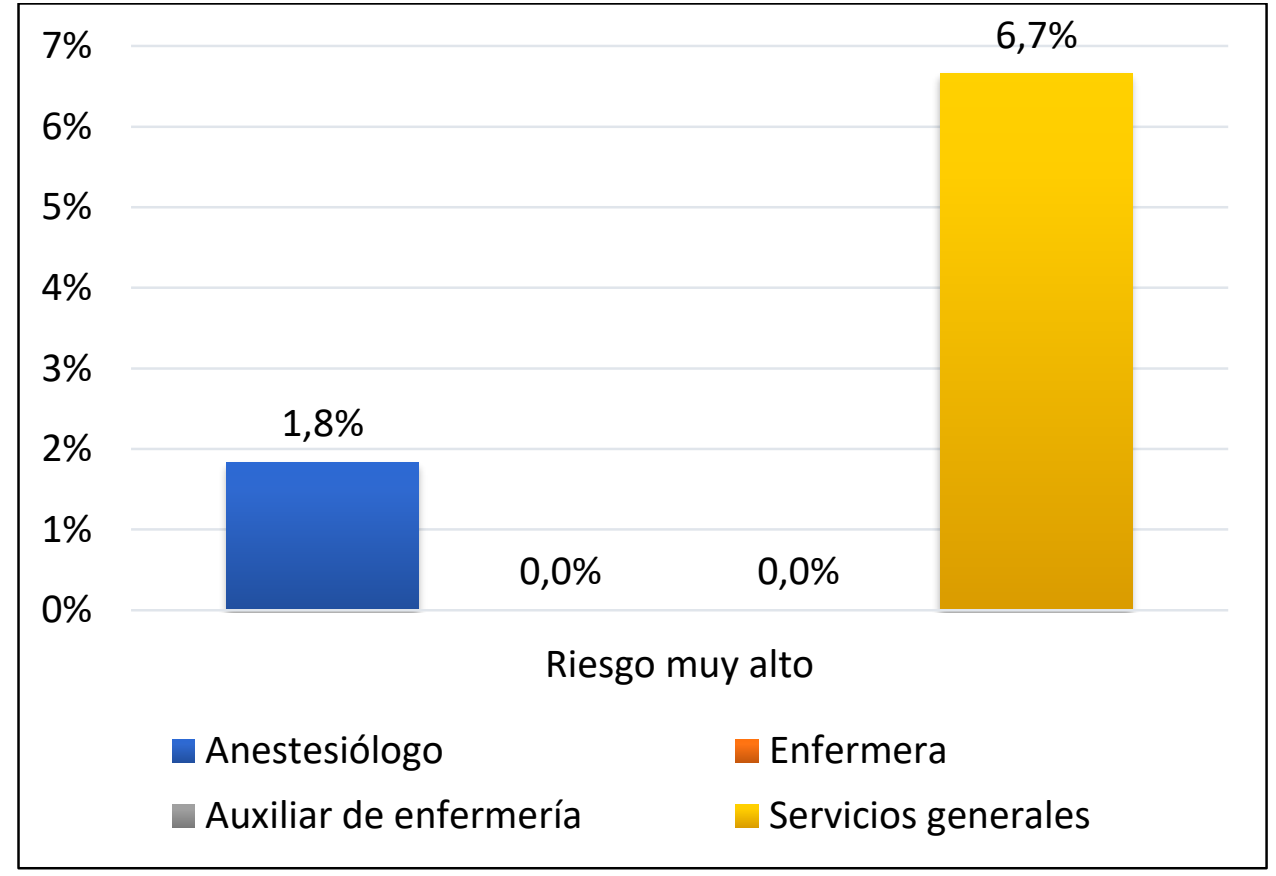

Figura 1. Distribución de riesgos muy altos en cada puesto de trabajo analizado Fuente: elaboración propia 


\section{Conclusiones}

- Se identificaron 284 factores de riesgos en total en los cuatro puestos de trabajo analizados del personal del centro quirúrgico.

- La mayor cantidad de riesgos alcanzaron un nivel aceptable en todos los cuatro puestos de trabajo analizados, los cuales representan el 54,6\% del total de riesgos identificados.

- Se presentaron riesgos muy altos únicamente en los puestos de Trabajo de Anestesiólogo (100\% de los peligros por agentes químicos) y Servicios generales (50\% de sus factores de riesgo ergonómicos), los cuales representan el 2,1\% de los riesgos identificados en los puestos de trabajo analizados.

- No se identificaron riesgos altos, pero sí un $21,8 \%$ y $21,5 \%$ de los riesgos se ubicaron en las categorías de riesgos notables y riesgos posibles, respectivamente.

- El $100 \%$ de los peligros por emergencias mayores, alcanzaron un riesgo notable; sin embargo, la intervención en estos únicamente puede direccionarse a la formación del personal en respuesta a emergencias, contingencias y continuidad del negocio.

- Los factores de riesgo por agentes biológicos, se ubicaron en el 82,4 \% de los riesgos notables. Por esta razón, deben enfocarse medidas de prevención en estos peligros.

- Los factores de riesgo psicosociales se encuentran en el 22,2 \% de los riesgos notables y el 27,8 \% de los riesgos posibles, razón por la cual estos seguirían en el siguiente orden de atención de peligros laborales.

- La mayor cantidad de factores de riesgos mecánicos y físicos, respectivamente el $100 \%$ y $92,9 \%$ de estos factores, se clasifican como riesgos aceptables.

\section{Referencias bibliográficas.}

AENOR. (2011). Prevención de riesgos laborales. $1^{\mathrm{a}}$ Ed. Málaga, España: Editorial Vértice.

Annalee, Y. y León, J. (1998). Asistencia sanitaria: naturaleza y problemas de salud en el trabajo. Enciclopedia de Salud y Seguridad en el Trabajo, 3 (97), 2.

Asfahl, R. y Rieske, D. (2010). Seguridad industrial y administración de la salud. $6^{\mathrm{a}}$ Ed. México, México: Editorial Pearson Educación.

Batalla, C., Bautista, J. y Alfaro, R. (2015). Ergonomía y evaluación del riesgo ergonómico. OPE-PROTHIUS, 1 (1), 1.

Cantos, C. (2012). Identificación, procedimientos para medición, procedimientos para evaluación, control y vigilancia: de los riesgos químicos y biológicos en el Hospital Universitario del Río. (Informe de tesis). Universidad Politécnica Salesiana del Ecuador, Cuenca, Ecuador.

Creus, A. y Mangosio, J. (2011). Seguridad e higiene en el trabajo: un enfoque integral. $1^{\mathrm{a}}$ Ed. Buenos Aires, Argentina: Grupo Editor Alfaomega. 
UBA. Método R.U.L.A. Hoja de Campo. Último acceso de 7 de mayo de 2018 en: http://www.fi.uba.ar/archivos/posgrados_apuntes_RULA_hoja_campo.pdf

Gómez, B. (2017). Manual de prevención de riesgos laborales. $1^{\text {a }}$ Ed. Barcelona, España: Marge Books.

Guardino, X. (1998). Gases anestésicos residuales. Enciclopedia de Salud y Seguridad en el Trabajo, 3 (97), 61-63.

ICONTEC (2011). NTC-ISO 31000: Gestión del Riesgo. Principios y Directrices. $2^{\mathrm{a}}$ Ed. Bogotá, Colombia: Editorial del Instituto Colombiano de Normas Técnicas y Certificación.

ICONTEC (2012). GTC 45: Guía para la Identificación de los peligros y la valoración de los Riesgos en Seguridad y Salud Ocupacional. $2^{\mathrm{a}}$ Ed. Bogotá, Colombia: Editorial del Instituto Colombiano de Normas Técnicas y Certificación.

INSHT. (2010). Tareas repetitivas II: Evaluación del riesgo para la extremidad superior. Último acceso de 5 de mayo de 2018 en: http://www.insht.es/Musculo Esqueleticos/Contenidos/Formacion\%20divulgacion/material\%20didactico/Tare as\%20repetitivas\%202_evaluacion.pdf

INSHT. (2011). Manipulación manual de cargas. Ecuación NIOSH. Último acceso de 5 de mayo de 2018 en: http://www.insht.es/MusculoEsqueleticos/Contenido s/Formacion\%20divulgacion/material\%20didactico/EcuacionNIOSH.pdf

INSHT. (2012). Nota Técnica de Prevención 936 Agentes químicos: evaluación cualitativa y simplicada del riesgo por inhalación (II). Modelo COSHH Essentials. Último acceso de 21 de mayo de 2018 en: http://www.insht.es/InshtWeb/Cont enidos/Documentacion/NTP/NTP/926a937/936w.pdf

INSHT. (2015). Exposición a agentes químicos. Evaluación cualitativa. Último acceso de 21 de mayo de 2018 en: http://riskquim.inssbt.es/riskquim/cb/

López, R. (2015). Ecuador define sus prioridades de investigación en salud. Último acceso de 2 de febrero de 2018 en: http://www.siicsalud.com/acise_viaje/ensiic as-profundo.php?id=118636

Mager, J. (1998). Perspectiva de los riesgos de origen químico en la asistencia sanitaria. Enciclopedia de Salud y Seguridad en el Trabajo, 3 (97), 55-60.

Ministerio de Salud del Ecuador (2015). Acuerdo Ministerial 5212. Tipología para homologar establecimientos de salud por niveles. Último acceso de 27 de marzo de 2018 en: http://instituciones.msp.gob.ec/cz6/images/lotaip/Enero2015/Acu erdo\%20Ministerial\%205212.pdf

Organización Iberoamericana de Seguridad Social. (2004). Los riesgos laborales de los 
médicos anestesistas. Último acceso de 20 de marzo de 2018 en: http://www.oiss.org/revista/?p=323

Ramos, F. y Hernández, A. (1998). Condiciones necesarias para el confort visual. Enciclopedia de Salud y Seguridad en el Trabajo, 2 (46), 8.

Rescalvo, F. (2004). Ergonomía y Salud. $1^{\text {a }}$ Ed. Castilla, España: Editorial de la Junta de Castilla y León.

Rubio, J. (2004). Métodos de Evaluación de Riesgos Laborales. 1 ${ }^{a}$ Ed. Madrid, España: Ediciones Díaz de Santos.

Rubio, J. et al (2005). Manual para la Formación de Nivel Superior en Prevención de Riesgos Laborales. $1^{\text {a }}$ Ed. Madrid, España: Ediciones Díaz de Santos.

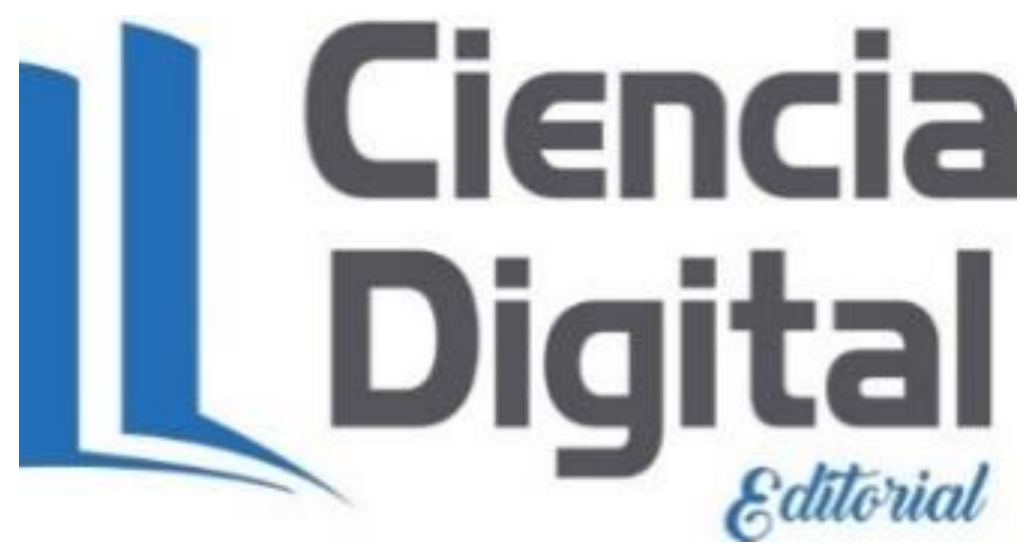


Para citar el artículo indexado.

Palacios L., Palacios E. \& Cáceres V. (2019) Evaluación de los riesgos de trabajo en el centro quirúrgico del Hospital Quito N.-1 Policía Nacional. Revista electrónica Ciencia Digital 3(1.1), 40-63.

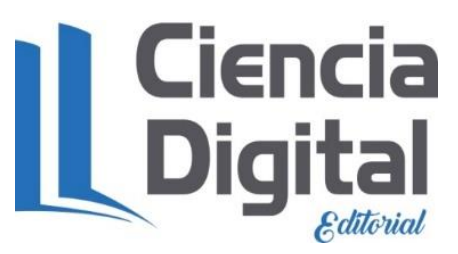

El artículo que se publica es de exclusiva responsabilidad de los autores y no necesariamente reflejan el pensamiento de la Revista Ciencia Digital.

El articulo queda en propiedad de la revista y, por tanto, su publicación parcial y/o total en otro medio tiene que ser autorizado por el director de la Revista Ciencia Digital.
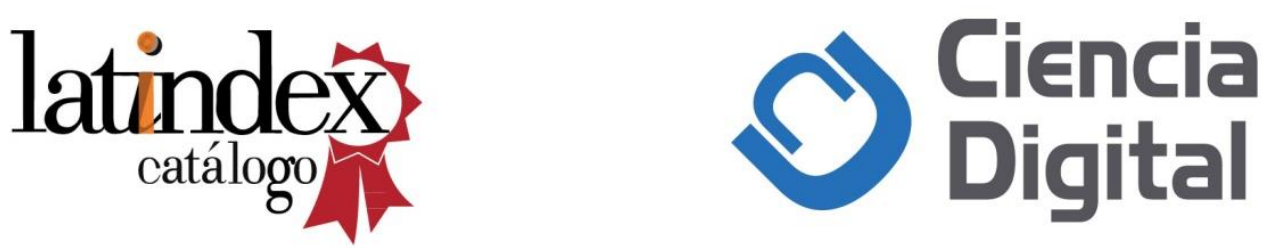